06

\title{
Регулярные микроструктуры на основе пленок полиэтилентерефталата
}

\author{
(C) В.Е. Асадчиков, ${ }^{1}$ С.А. Бедин, ${ }^{1,2}$ А.Б. Васильев, ${ }^{1}$ Ю.В. Григорьев, ${ }^{1}$ В.П. Назьмов ${ }^{3}$ \\ ${ }^{1}$ Институт кристаллографии им. А.В. Шубникова ФНИЦ „Кристаллография и фотоника“ РАН, Москва, Россия \\ ${ }^{2}$ Московский педагогический государственный университет, Москва, Россия \\ ${ }^{3}$ Институт ядерной физики им. Г.И. Будкера СО РАН, Новосибирск, Россия \\ E-mail: asad@crys.ras.ru
}

Поступило в Редакцию 12 декабря 2018 г.

В окончательной редакции 12 декабря 2018 г.

Принято к публикации 13 декабря 2018 г.

Разработан метод формирования регулярных диэлектрических и металлических микроструктур на основе пленок полиэтилентерефталата, облученных на источнике синхротронного излучения через маску с последующим травлением. Для исследования их геометрических параметров использована растровая электронная микроскопия.

DOI: 10.21883/PJTF.2019.05.47399.17638

Регулярные ориентированные микроструктуры (диэлектрические, металлические, а также композитные) перспективны для создания и использования в качестве элементов устройств управления оптическим излучением и хранения информации $[1,2]$. Такие структуры можно получить в результате синтеза с использованием в качестве несущих элементов предварительно подготовленных полимерных пленок. Создание в пленках каналов или контейнеров может быть проведено в результате облучения на циклотроне тяжелыми ионами или на синхротроне жестким рентгеновским излучением через маску с калиброванными отверстиями с последующим травлением $[3,4]$. Идентичность и регулярность размеров создаваемых в пленках микроструктур является важным критерием возможности их практического применения.

Задача настоящей работы состоит в получении регулярных, в том числе несквозных, пор в пленке полиэтилентерефталата (ПЭТФ) толщиной $10 \mu \mathrm{m}$ с использованием синхротронного излучения, а также исследовании возможности создания диэлектрических и металлических микроструктур на их основе.

Использовалось синхротронное излучение рентгеновского диапазона, генерируемое ускорителем электронов ВЭПП-3 и выводимое в „,““-канал, соединенный со станцией рентгеновской литографии. Экспозиционная доза $36000 \mathrm{~mA} / \mathrm{min}$, энергия электронов $1.2 \mathrm{GeV}$, максимум на длине волны $3.5 \AA$. Доза поглощенного излучения в центре пучка составляла около $61 \mathrm{~kJ} / \mathrm{cm}^{3}$ на лицевой и $52 \mathrm{~kJ} / \mathrm{cm}^{3}$ на тыльной стороне пленки. Локальная модификация пленки ПЭТФ (формирование скрытого изображения) с целью получения пор проводилась посредством облучения через рентгеновскую маску, представляющую собой двумерный массив сквозных микроотверстий в танталовой мембране толщиной $2 \mu \mathrm{m}$ [3]. Плотность пор определялась параметрами маски и составляла $10^{6} \mathrm{~cm}^{-2}$. Микроотверстия диаметром $0.5 \mu \mathrm{m}$ распределялись регулярно по двум координатам в плос- кости маски и были скомпонованы в поля квадратной формы размером $3 \times 3 \mathrm{~mm}$, расстояние между центрами отверстий маски $2.9 \mu \mathrm{m}$. Поля отстояли друг от друга на расстояние $1 \mathrm{~mm}$ по обеим координатам. Кассета с зафиксированными исходными пленками и маской была ориентирована перпендикулярно направлению падающего луча синхротронного излучения, диаметр облученной зоны составлял $16 \mathrm{~mm}$. Выявление треков проводилось путем травления пленки в $10 \%$ водном растворе $\mathrm{NaOH}$ при температуре $60^{\circ} \mathrm{C}$ в течение $30 \mathrm{~min}$, после чего она промывалась в дистиллированной воде.

Для изучения морфологии, геометрических параметров пленок и элементного состава полученных микроструктур применялся растровый электронный микроскоп (РЭМ) FEI Scios $(30 \mathrm{kV})$ и РЭМ FEI Quanta $2003 \mathrm{D}(30 \mathrm{kV})$ с энергодисперсионным детектором EDAX. Специальная пробоподготовка не проводилась.

На рис. 1 представлены микрофотографии поверхности и скола пленки. С целью изучения внутренней микроструктуры применялся метод предварительного УФ-облучения [5], который позволил сделать ее более хрупкой и произвести ровный скол по центру пор. Из рис. 1, а следует, что диаметр пор составляет около $1.4 \mu \mathrm{m}$, что больше величин, характерных для пор на рентгеновской маске. Поскольку принудительное перемешивание раствора в процессе травления не применялось, скорость травления определяется диффузионной компонентой, которая равновероятна во всех направлениях в объеме облученной зоны и зависит только от величины дозы. Как следствие, наблюдается растравливание облученной зоны по причине диссипации энергии в область геометрической тени микроотверстий, находящихся на рентгеновской маске, что обусловлено возникновением фотоэлектронов и дифракцией рентгеновского излучения на краях облученной зоны пленки. Рис. $1, b$ показывает, что облученные и протравленные зоны имеют шероховатую, а не гладкую поверхность. 

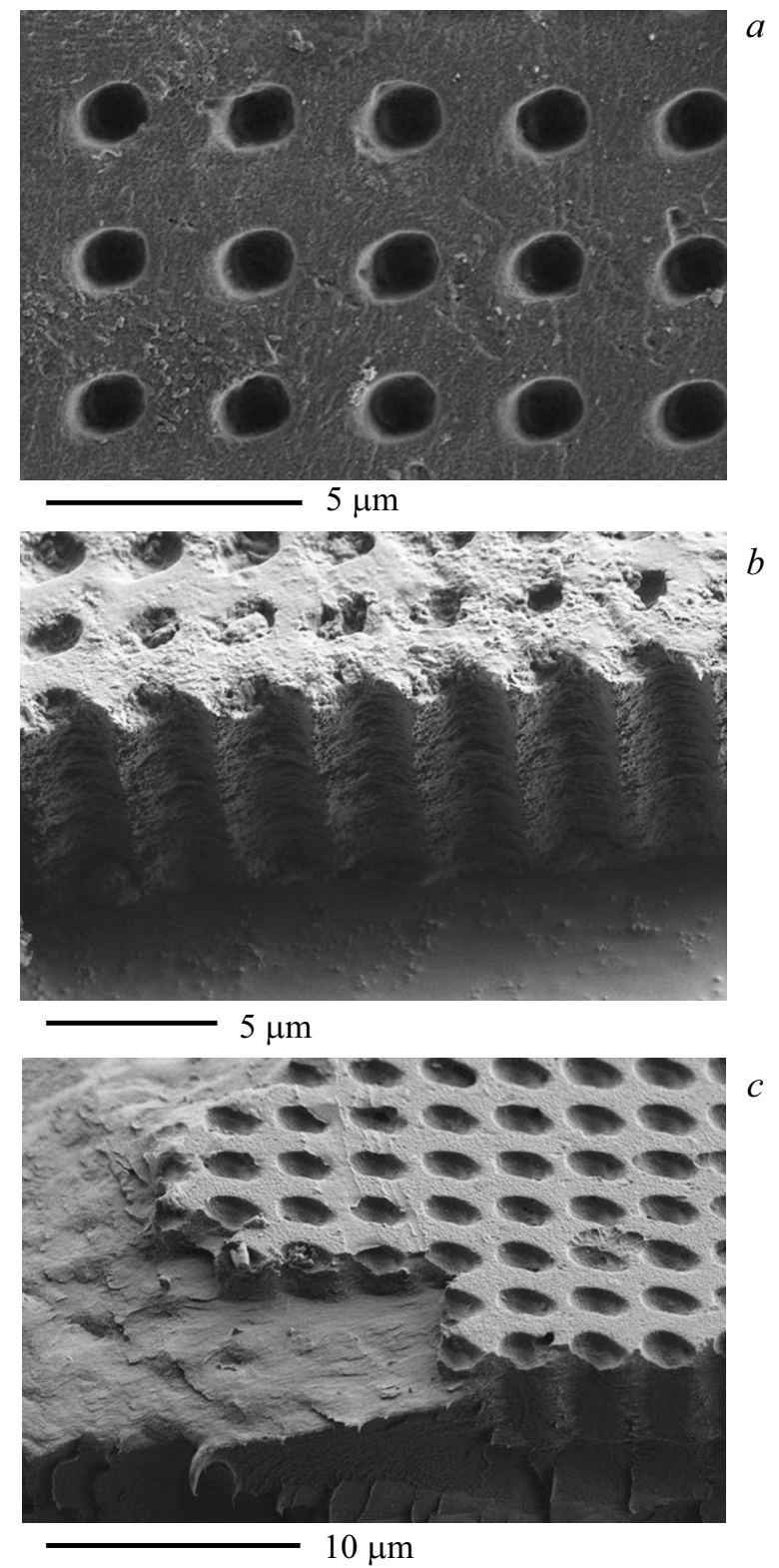

Рис. 1. РЭМ-изображения поверхности $(a)$, скола в центре $(b)$ и на краю $(c)$ облученной и протравленной полимерной пленки.

Развитая поверхность способствует образованию в „устьях“ облученных зон кристаллических микроструктур. После травления в растворе щелочи при высыхании пленок в стационарных условиях на них были получены микрокристаллы терефталата натрия, характеризующиеся огранкой и частично покрытые промежуточным слоем (размеры от 0.05 до $1 \mu \mathrm{m}$, рис. 2). В [6] было отмечено, что на поверхности сквозных пор пленки ПЭТФ можно формировать нитевидные структуры с диаметром порядка диаметра поры и длиной, существенно превышающей толщину пленки. В нашем же случае после облучения и вымывания легкой фракции молекулярных фрагментов пористая пленка даже с несквоз- ными порами может служить матрицей для заполнения материалом из ионного раствора или газовой фазы [7].

При уменьшении приблизительно в 10 раз дозы облучения, что происходит на периферии рентгеновского пучка, травление при тех же условиях позволяет получить несквозные поры (рис. $1, c$ ). Именно на базе несквозных пор полимера нами методом электрохимического осаждения были выращены микроструктуры из железа. Для этого на пленку с несквозными порами наносился тонкий слой золота для образования токопроводящей пленки. Затем она помещалась в электрохимическую ячейку и проводился процесс осаждения железа при комнатной температуре в потенциостатическом режиме в течение $30 \mathrm{~min}$ по методике [8] с использованием электролита следующего состава: $\mathrm{FeSO}_{4} \cdot 7 \mathrm{H}_{2} \mathrm{O}-$ $120 \mathrm{~g} / 1, \mathrm{H}_{3} \mathrm{BO}_{3}-45 \mathrm{~g} / \mathrm{l}$, аскорбиновая кислота $-0.5 \mathrm{~g} / \mathrm{l} ;$ $\mathrm{pH}=2.3$. Для визуализации полученных структур проводились их фиксация напылением слоя меди толщиной $20 \mu \mathrm{m}$ и растворение пленки в концентрированном растворе щелочи (рис. 3). По данным, полученным на атомно-силовом микроскопе, высота металлических микроструктур составляет порядка $0.2 \mu \mathrm{m}$.

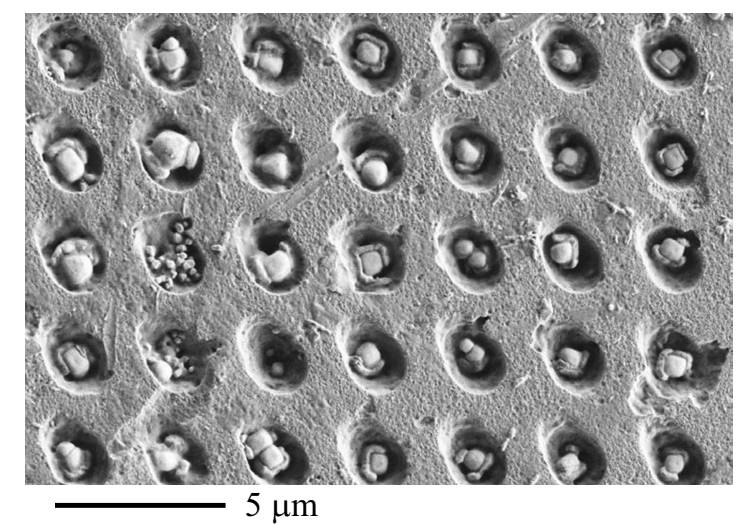

Рис. 2. РЭМ-изображение микрокристаллов терефталата натрия в устьях пор.

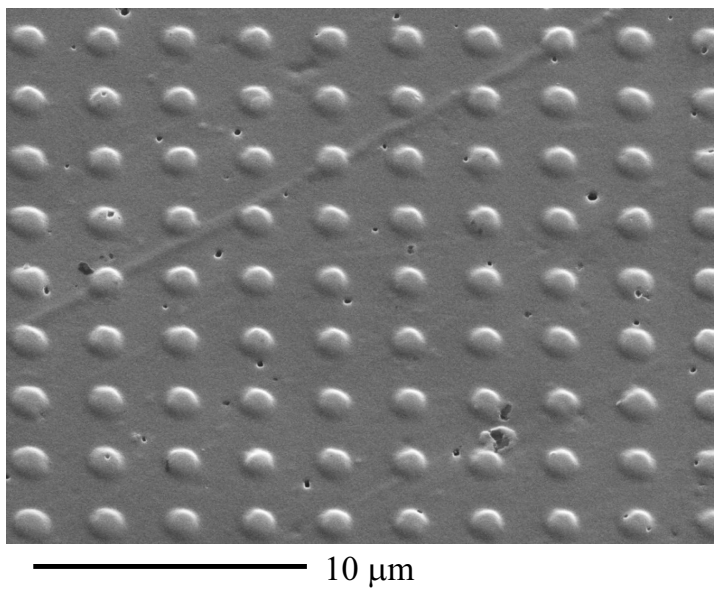

Рис. 3. РЭМ-изображение микрокристаллов из железа, полученных методом электроосаждения в несквозных порах. 
Представленные в работе результаты могут быть применены при создании оптических элементов с селективными свойствами, например фотонных кристаллов, в том числе двумерно упорядоченных. Микроструктуры из нелинейных диэлектриков типа фазированной антенной решетки позволяют значительно увеличить сигнал второй гармоники по сравнению с генерацией в однородном объеме, что существенно расширяет возможности регистрации излучения за счет преобразования его частоты [9].

Металлические микроструктуры, полученные на базе полимерных пленок, перспективны для разработки систем магнитной памяти с высокой плотностью информации. Применение для осаждения магнитных структур тонких пленок немагнитных металлов, а также использование сквозных пор может обеспечивать магнитную изолированность отдельных функциональных элементов. Использование несквозных пор может обеспечить дополнительные преимущества, связанные с уменьшением их размеров.

Работа выполнена при поддержке Министерства науки и высшего образования РФ в рамках выполнения работ по государственному заданию ФНИЦ „Кристаллография и фотоника“ РАН в части выращивания диэлектрических и металлических микрокристаллов и РФФИ (грант 18-29-20090) в части получения регулярных мембран и рассмотрения возможности их применимости для решения задач фотоники.

\section{Список литературы}

[1] Пул Ч., Оуэнс Ф. Нанотехнологии. М.: Техносфера, 2005. $336 \mathrm{c}$.

[2] Семенов В.Г., Бедин С.А., Асадчиков В.Е., Васильев А.Б. // Письма в ЖТФ. 2018. Т. 44. В. 14. С. 66-72.

[3] Goldenberg B.G., Lemzyakov A.G., Nazmov V.P., Pindyurin V.F. // Phys. Procedia. 2016. V. 84. P. 205-212.

[4] Апель П.Ю., Дмитриев С.Н. Трековые мембраны // Мембраны и мембранные технологии / Отв. ред. А.Б. Ярославцев. М.: Научный мир, 2013. С. 126.

[5] Orelovitch O.L., Apel P.Yu., Sartowska B. // Mater. Chem. Phys. 2003. V. 81. N 2-3. P. 349-351.

[6] Васильев А.Б., Березкин В.В., Артемов В.В., Мчедлишвили Б.В. // Мембраны и мембранные технологии. 2015. Т. 5. № 2. C. $120-124$.

[7] Беляев М.В. // Теоретические основы хим. технологии. 1996. T. 30. № 4. С. 360-365.

[8] Фролов К.В., Загорский Д.Л., Любутин И.С., Коротков В.В., Бедин С.А., Сульянов С.Н., Артемов В.В., Мчедлишвили Б.В. // Письма в ЖЭТФ. 2014. Т. 99. В. 10. C. $656-663$.

[9] Гапоненко С.В., Розанов Н.Н., Ивченко Е.Л., Федоров А.В., Баранов А.В., Бонч-Бруевич А.М., Вартанян Т.А., Пржибельский С.Г. // Оптика наноструктур. СПб.: Недра, 2005. $326 \mathrm{c}$. 